\title{
Histomorphometric Evaluation of Allogeneic Transplantation of Bone Marrow Mesenchymal Stem Cells in Azoospermic Mice Model
}

\author{
Ahmad Mozafar ${ }^{1,2}$, Davood Mehrabani ${ }^{3, *}$, Akbar Vahdati ${ }^{1,2}$, Ebrahim Hosseini ${ }^{1,2}$, \\ Mohsen Forouzanfar ${ }^{4}$
'Department of Biology, Fars Science and Research Branch, Islamic Azad University, Fars, Iran
${ }^{2}$ Department of Biology, Shiraz Branch, Islamic Azad University, Shiraz, Iran
${ }^{3}$ Stem Cell Technology Research Center, Shiraz University of Medical Sciences, Shiraz, Iran
${ }^{4}$ Department of Biology, Marvdasht Branch, Islamic Azad University, Marvdasht, Iran
${ }^{*}$ Corresponding author. E-mail: transgeneshiraz@gmail.com

Received date: Oct 31, 2017; Revised date: Apr 27, 2018; Accepted date: May 15, 2018

\section{Abstract}

$\mathrm{B}$ ACKGROUND: Stem cell-based therapy is one of the newest and evolving techniques in reproductive medicine. The aim of this study was to investigate the effect of allogeneic bone marrow mesenchymal stem cells (BM-MSCs) transplantation on the testis of busulfan induced azoospermia in Balb/C mice.

METHODS: Eighteen adult Balb/C mice were divided into three equal groups including control, busulfan and busulfan+cell therapy (busul $+\mathrm{CT}$ ). For induction of azoospermia, busulfan and busul+CT groups received two injections of $10 \mathrm{mg} / \mathrm{Kg}$ of busulfan intraperitoneally with 21 days interval. In the cell therapy group 35 days after the last injection of busulfan, cluster of differentiation (CD) $90^{+} /$ CD34-CD45- BM-MSCs were injected into the efferent duct of testis. Eight weeks after the BM-MSCs therapy, mice were sacrificed and tissues were taken for histological and histomorphometric evaluations.

\section{Introduction}

Nowadays one of the problems of human society is the infertility problem. Approximately 10 to 15 percent of infertility in men is due to obstructive or non-obstructive azoospermia.(1) Many efforts are being made today to treat azoospermia, especially its non-obstructive type.(2) Cancer is one of the most common diseases around the world, and
RESULTS: In busul+CT group, cellular and total diameters and cellular and cross-sectional areas significantly increased in comparison to busulfan group ( $p<0.001$ ), but there were no significant differences between busul $+\mathrm{CT}$ and control group $(p>0.05)$. Numerical density and tubular count per area unit in busul $+\mathrm{CT}$ and control groups were significantly less than busulfan group $(p<0.001)$, but there were no significant difference between busul $+\mathrm{CT}$ and control group $(p>0.05)$. The luminal diameter and area showed no significant change in all groups $(p>0.05)$. In busul $+\mathrm{CT}$ group, spermatogenesis index significantly increased when compared to busulfan and control groups $(p<0.001$ and $p<0.05$, respectively).

CONCLUSION: Histomorphometric findings showed $\mathrm{CD} 90^{+} / \mathrm{CD} 34 / \mathrm{CD} 45^{-} \mathrm{BM}-\mathrm{MSC}$ s transplantation on the testis of busulfan-induced azoospermic in Balb/C mice recovered spermatogenesis.

KEYWORDS: mesenchymal stem cell, cell therapy, azoospermia, busulfan, mouse

Indones Biomed J. 2018; 10(2): 171-8 in many cases chemotherapy is used to treat it with drugs such as busulfan.(3) Infertility resulting from the use of drugs such as busulfan in the chemotherapy of people with cancer is considered to be a significant concern in medical circles.(4) Busulfan (1,4-Butanediol dimethanesulfonate) is an anti-neoplasia and DNA alkylated drug used to treat myelogenous leukemia and cancer treatments. Although busulfan does not destroy all spermatogonia, it can cause temporary or permanent infertility.(5) 
After treatment with busulfan, the most important factor in the degeneration of germ cells is the elimination of the balance between reproduction and apoptosis and germinal epithelium. Animal experiments indicate the ability of stem cells to restore fertility after chemotherapy in animals.(6) Various sources of use for stem cells are used, including embryonic stem cells or pluripotent stem cells, but the use of mesenchymal stem cells (MSCs) is of great interest because of its ease of access and working with it. MSCs can be obtained from various sources such as bone marrow, adipose tissue, dental pulp, and menstrual blood, all of which have a high ability to differentiate into different tissues. $(7,8)$

MSCs have been shown to secrete cytokines and growth factors that have anti-inflammatory, immunemodulating, anti-apoptotic, and proliferative effects. Some reports confirm the positive effects of MSCs on the process of repairing body tissues.(9) Meanwhile, bone marrow MSCs (BM-MSCs) have been considered by many researchers because of their high ability to differentiate into a variety of cell lines.(10)

The use of BM-MSCs, due to the possibility of proper extraction and proliferation, as well as the ability of the differentiation of this group of cells into different tissues, has made them an appropriate candidate for cell therapy. $(2,5)$ In this study, the effect of transplantation of cluster of differentiation (CD) $90^{+} / \mathrm{CD} 34 / \mathrm{CD} 45^{-} \mathrm{BM}-\mathrm{MSCs}$ on the treatment of busulfan induced azoospermia in $\mathrm{Balb} / \mathrm{C}$ mice was investigated.

\section{Methods}

\section{Animals}

Eighteen male adult Balb/C mice ( $30 \pm 5 \mathrm{~g})$, were provided from Laboratory Animal Center of Shiraz University of Medical Sciences. The animals were kept at controlled temperature $\left(22 \pm 2^{\circ} \mathrm{C}\right)$, humidity $(55 \pm 5 \%)$ and lightening (12 hours light/dark; from 07:00 a.m. to 19 p.m.) They had free access to food and water. The study was undertaken based on rules and regulations approved by the Ethics Committee for Animal Research at Islamic Azad University of Shiraz, Iran (Ethical code no: IR.Miau 1396.602).

\section{Experimental Design}

The mice were randomly assigned into three equal groups of control, busulfan and busul+CT ( $\mathrm{n}=6$ in each group). In control group, no busulfan was administered. In busulfan and busul+CT groups, two doses of $10 \mathrm{mg} / \mathrm{Kg}$
Busilvex ${ }^{\circledR}$ busulfan (Pierre Fabre Medicament, BoulogneBillancourt, France) with 21 days interval were injected intraperitoneally for induction of azoospermia. Based on previous studies, the dose of busulfan was designated in order to induce azoospermia mice model.(11,12) In the first of experiment, the first dose of busulfan $(10 \mathrm{mg} / \mathrm{Kg})$ was injected. In busulfan and busul $+\mathrm{CT}$ therapy groups and 21 days later the second dose of busulfan $(10 \mathrm{mg} / \mathrm{Kg})$ was also done, intraperitoneally. In busul+CT group after 35 days the second injection, $\mathrm{CD} 90^{+} / \mathrm{CD} 34 / \mathrm{CD} 45^{-} \mathrm{BM}-\mathrm{MSC}$ s were injected into the efferent duct of both testes and 8 weeks after the BM-MSCs therapy all groups were sacrificed for testes removal. On the day of sampling, the sacrifice was undertaken using ether and cervical dislocation. For histomorphometric and histological evaluations, the removed testes were fixed in $10 \%$ formalin buffer.

\section{Stem Cells Extraction and Culture}

Stem cells were isolated from femurs of one donor euthanized Balb/C mouse. In sterile condition the two ends of the bone were cut and injected into the Dulbecco's modified eagle medium (DMEM) without fetal bovine serum (FBS) and penicillin-streptomycin antibiotics. Bone marrow was collected and then, the falcon contains bone marrow cells centrifuged at speeds of $1200 \mathrm{rpm}$ for 5 minutes, after that, the supernatant phase was removed by pipette and the DMEM medium was added to the cells in the falcon. Then cell suspension was transferred to 25 $\mathrm{cm}^{2}$ flask containing DMEM medium with $10 \%$ FBS and $1 \%$ penicillin-streptomycin antibiotic. And flask was incubated at $37^{\circ} \mathrm{C}$ and standard humidity and $5 \%$ carbon dioxide concentration. The culture medium was changed after the first 24 hours and then every 72 hours under sterile conditions. After increasing the density of the cells adhering to the flask to $80 \%$, the cells were passaged using trypsin enzyme, adding the trypsin enzyme for 3 minutes; the cells sticking to the flask floor were separated. Then, to neutralize the effect of trypsin enzyme, $2 \mathrm{~mL}$ of culture medium containing 10\% FBS was added to the flask. Cells isolated from the medium were called the first passage, and these actions continued until the third passage.(7)

\section{MSC Characterization: Real Time-Polymerase Chain Reaction (RT-PCR) Evaluation}

To confirm the presence of bone marrow mesenchymal stem cells and the absence of hematopoietic stem cells in this study, RT-PCR was used. In this regard, the presence of CD90, which is a specific protein of mesenchymal stem cells and the absence of CD34 and CD45, which are the 
specific proteins of the hematopoietic stem cells were investigated.

Cells from the third passage were used. In the first step, RNA was extracted by column method using kit. In the second step, cDNA was constructed in reverse transcription reaction. Then PCR in thermal cycler machine using $200 \mu \mathrm{M}$ dNTPs, $2.5 \mu \mathrm{M}$ cDNA, $0.5 \mu \mathrm{M} \mathrm{MgCl} 2,25 \mu \mathrm{LTaq}$ DNA polymerase, PCR buffer and forward and reverse primers CD34,CD45 and CD90 was performed (Table 1). The microcentrifuge tubes containing the resultant mixing were transferred into thermocycle. Thirty thermal cycles were performed as follow: 5 minutes at $95^{\circ} \mathrm{C}$ for the initial denaturation and 30 seconds at $95^{\circ} \mathrm{C}$ for denaturation were performed.

Table 1. Sequences of RT-PCR primers used to quantify the expression of BM-MSCs specific marker (CD90) and hematopoietic stem cells' specific marker (CD45 and CD34) in Mouse.

\begin{tabular}{ll}
\hline Gene Name-Direction & \multicolumn{1}{c}{ Primer Sequence } \\
\hline CD34-Forward & AATGAGTCTGTTGAGGAA \\
CD34-Reverse & CTGTCTGAAGTAGTAGGC \\
CD45-Forward & AAGTGGATGTCTATGGTTA \\
CD45-Reverse & GAAGGAAGTCTCTGGTAT \\
CD90-Forward & GAAGACAAGGAGCCAGAAC \\
CD90-Reverse & GCAAGGGAAAGAAGAATAAAGG \\
\hline
\end{tabular}

At next step, annealing was performed at $64^{\circ} \mathrm{C}, 62^{\circ} \mathrm{C}$, and $61^{\circ} \mathrm{C}$ for 30 seconds, respectively. Finally, extension was accomplished at $72^{\circ} \mathrm{C}$ for 30 seconds and the final polymerization at $72^{\circ} \mathrm{C}$ for 5 minutes was done. The electrophoresis of the PCR product was performed on $1.5 \%$ agarose gel containing ethidium bromide and the obtained bands were evaluated.

\section{Osteogenic and Adipogenic Differentiation}

After achieving $80 \%$ confluence, the $\mathrm{CD} 90^{+} / \mathrm{CD} 34 \%$ CD45- BM-MSCs were cultivated in the osteogenic and adipogenic differentiation medium. For osteogenic medium, DMEM with $15 \%$ of FBS, $200 \mu \mathrm{M}$ L-ascorbic acid (Wako Chemicals, Richmond, VA, USA), $100 \mathrm{nM}$ dexamethasone (Sigma-Aldrich, St Louis, USA), $10 \mathrm{mM}$ glycerolphosphate (Sigma-Aldrich) and for adipogenic medium DMEM with $15 \%$ of FBS, $200 \mu \mathrm{M}$ indomethacin (Sigma-Aldrich), and $100 \mathrm{nM}$ dexamethasone, $100 \mu \mathrm{M}$ L-ascorbic acid and $0.2 \mathrm{mM} \mathrm{L-glutamine} \mathrm{(Sigma-Aldrich)} \mathrm{were} \mathrm{used.}$ Differentiation medium was changed twice a week for 21 days. Before staining, the cells were fixed for 10 minutes by $10 \%$ formalin solution. Alizarin Red staining was used to indicate the calcified extracellular matrix and osteogenic differentiation and for adipogenic differentiation Oil Red O staining was applied that specifically stains lipid droplets.

\section{Surgical and Transplantation Procedures}

For $\mathrm{CD} 90^{+} / \mathrm{CD} 34 / \mathrm{CD} 45^{-} \mathrm{BM}-\mathrm{MSC}$ Transplantation, 35 days after last busulfan injection, the mice were anesthetized using $5 \mathrm{mg} / \mathrm{Kg}$ ketamine (Alfazyne, Woerden, Netherlands) and $20 \mathrm{mg} / \mathrm{Kg}$ xylasein (Alfazyne). Then, by providing a $2 \mathrm{~cm}$ incision in the posterior abdominal region, access to the peritoneum was provided. Then gently without damaging to the epididymis, the testicles were immobilized by a triangular plastic piece (Figure 1A). To determine the injected, BM-MSCs were mixed with sterile trypan blue $(1: 1, \mathrm{v} / \mathrm{v})$. Also, with using a pipette, $100 \mu \mathrm{L}$ of suspension (106 BM-MSCs) was injected into the efferent duct of the both testes till most of seminiferous tubules were filled. Consequently, the testicle was returned to the abdominal cavity and the abdominal wall and skin were stitched (Figure 1B).(13)
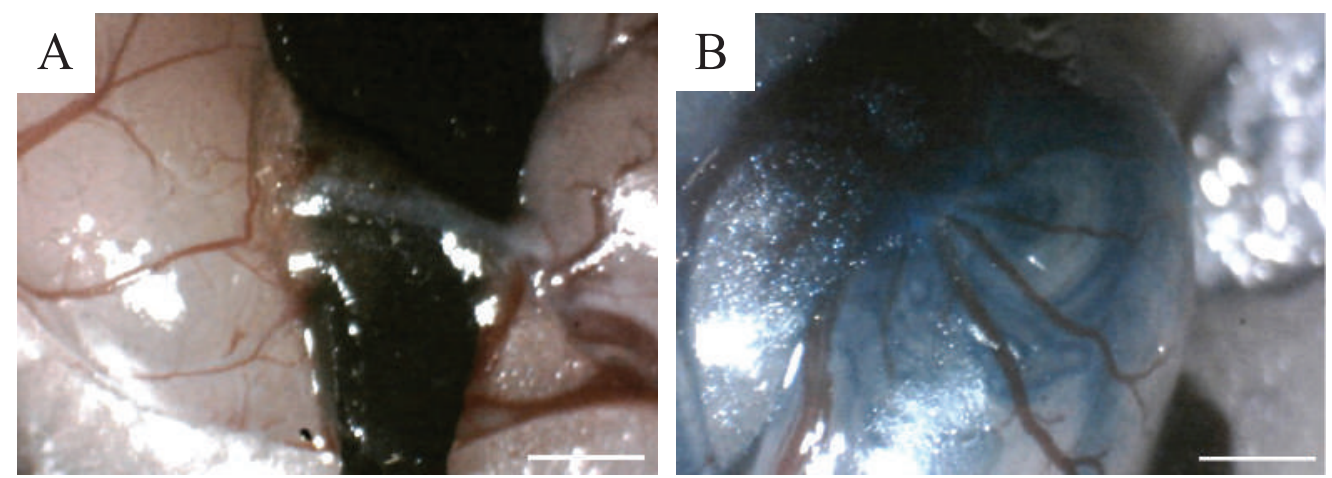

Figure 1. Transplantation of BM-MSCs in seminiferous tubules of azoospermic mouse. A: To distinguish the translucent efferent duct from the fat tissue and the membrane around it, a hard black plastic triangle was placed under the efferent duct; B: After Injection of $\mathrm{CD}^{+} / \mathrm{CD} 34 \% \mathrm{CD} 45-\mathrm{BM}-\mathrm{MSC}$ suspension into efferent duct of mouse testis seminiferous tubules were partially filled. White bars, $1 \mathrm{~mm}$. 


\section{Histomorphometric Assessment}

After fixation and alcohol dehydration of testicular tissue, it was embedded in paraffin and for tissue section, five horizontal cross-sections were conducted as described by Panahi, et al. The sections were $5-\mu \mathrm{m}$ in thickness and staining was conducted using hematoxylin-eosin (H\&E) and was visualized using a light microscope Model CX21 (Olympus, Tokyo, Japan). The presence of spermatogonia, spermatocytes and spermatids were evaluated in all tubules. The inner, outer and total diameters were determined in all tubules conducting 10 circular transverse sections from different regions of the tubules. The total and lumen diameters were assessed in transverse sections by Dinocapture software version 2.0 (Dino-Eye, San-Chung, Taiwan). By taking the average of two diameters at right angles including $\mathrm{D}_{1}+\mathrm{D}_{2} / 2$ and $\mathrm{L}_{1}+\mathrm{L}_{2} / 2$, the averages of total and Lumen diameters of seminiferous tubules (D and L) were clarified, respectively.(12)

By use of the diameter data, the luminal, cellular (germinal epithelium) and cross sectional areas were determined. In the seminiferous tubules, the cross-sectional area (Ac) was evaluated using the equation of $A c=\pi D^{2} / 4$; where $\mathrm{D}$ was considered as the mean diameter of tubules and $\pi$ was regarded as equivalent to 3.142 . The seminiferous tubulecount per unit area was also determined. The sections of seminiferous tubules per unit area were defined by use of an unbiased counting frame. In seminiferous tubules, numerical density $\left(\mathrm{N}_{\mathrm{v}}\right)$ was considered as a number of tubules per unit volume and it was assessed by the following equation: $\mathrm{N}_{\mathrm{V}}=\mathrm{N}_{\mathrm{A}} / \mathrm{D}+\mathrm{T}$, where, $\mathrm{N}_{\mathrm{A}}$ denotes to the number of profiles per unit area, the tubule mean diameter was represented by $\mathrm{D}$, and $\mathrm{T}$ revealed the mean thickness of the section.(12)

The spermatogenesis index included the presence of spermatogenic cells throughout all testicular tissue compromising the types of cells, the number of cell layers, and the presence of late spermatids in the tubules. Therefore, the number of late spermatids if available were counted and then seminiferous tubules were classified based on the scale of 0-7 regarding spermatogenic potential, while the spermatogenesis index was modified. The scale of 0 to 7 was defined as follows: $0=$ no germinal cells; $1=$ only spermatogonia cells; $2=$ both spermatogonia and spermatocytes cells; $3=$ spermatogonia, spermatocytes, and less than 50 late spermatids cells per tubule; 4=spermatogonia, spermatocytes, and 50-74 late spermatids cells per tubule; 5=spermatogonia, spermatocytes and 75-99 late spermatids cells per tubule; $6=$ spermatogonia, spermatocytes and 100-149 late spermatids cells per tubule;
$7=$ all germinal cell types and more than 150 late spermatids cells per tubule. $(11,12)$

\section{Statistical Analysis}

All data were presented as means and standard error (SE). Kolmogorov-Smirnov test was performed to normalization of data. Statistical analysis was done with one-way ANOVA and post-hoc Tukey test by SPSS software ver. 20 (SPSS Inc., Chicago, USA). The Mann-Whitney U test was used to assess spermatogenesis index. A $p$-value of less than 0.05 was regarded statistically significant. The graphs are designed by GraphPad Prism software ver. 5.01 (GraphPad Software Inc., San Diego, CA, USA).

\section{Results}

Morphologically, cells in the third passage have a fibroblastic appearance that is one of the main characteristics of MSCs (Figure 2A). Also, The results showed that after examination of BM-MSCs by RT-PCR the presence of surface marker for BM-MSCs (CD90) and the absence of surface factors of hematopoietic stem cells (CD34 and CD45) were identified (Figure 2B). The presence of calcium deposits in osteogenic differentiation medium after 21 days with alizarin red staining indicated the characteristics of osteoblasts in comparison with control (Figure 2C and 2D). In the adipogenic differentiation medium, the presence of lipid droplets after Oil Red O staining in the same period confirmed by the differentiation of these cells into adipoblasts as well (Figure 2E).

Histologic findings showed that in the control group, Spermatogenesis was performed completely and spermatogenic cells with Sertoli cells were observed in seminiferous tubules (Figure 3A). In the busulfan group, the spermatogenic cells were significantly reduced, and the large vacuoles space were observed in the germinal epithelium of seminiferous tubules. A small number of spermatogonial cells were located on the basement membrane, and Sertoli cells were visible and spermatogenesis was completely degraded (Figure 3B). In the busul+CT group, the vacuolate space was eliminated, and in most seminiferous tubules, there were a variety of cell lines including spermatogonia, spermatocyte, spermatid and sperm (Figure 3C).

Histomorphometric findings showed that Total and cellular diameters and cellular and cross-sectional areas were significantly increased in busul $+\mathrm{CT}$ group in comparison to the busulfan group $(p<0.001)$ and there was no significant difference in busul $+\mathrm{CT}$ and control groups $(p>0.05)$ (Figure 

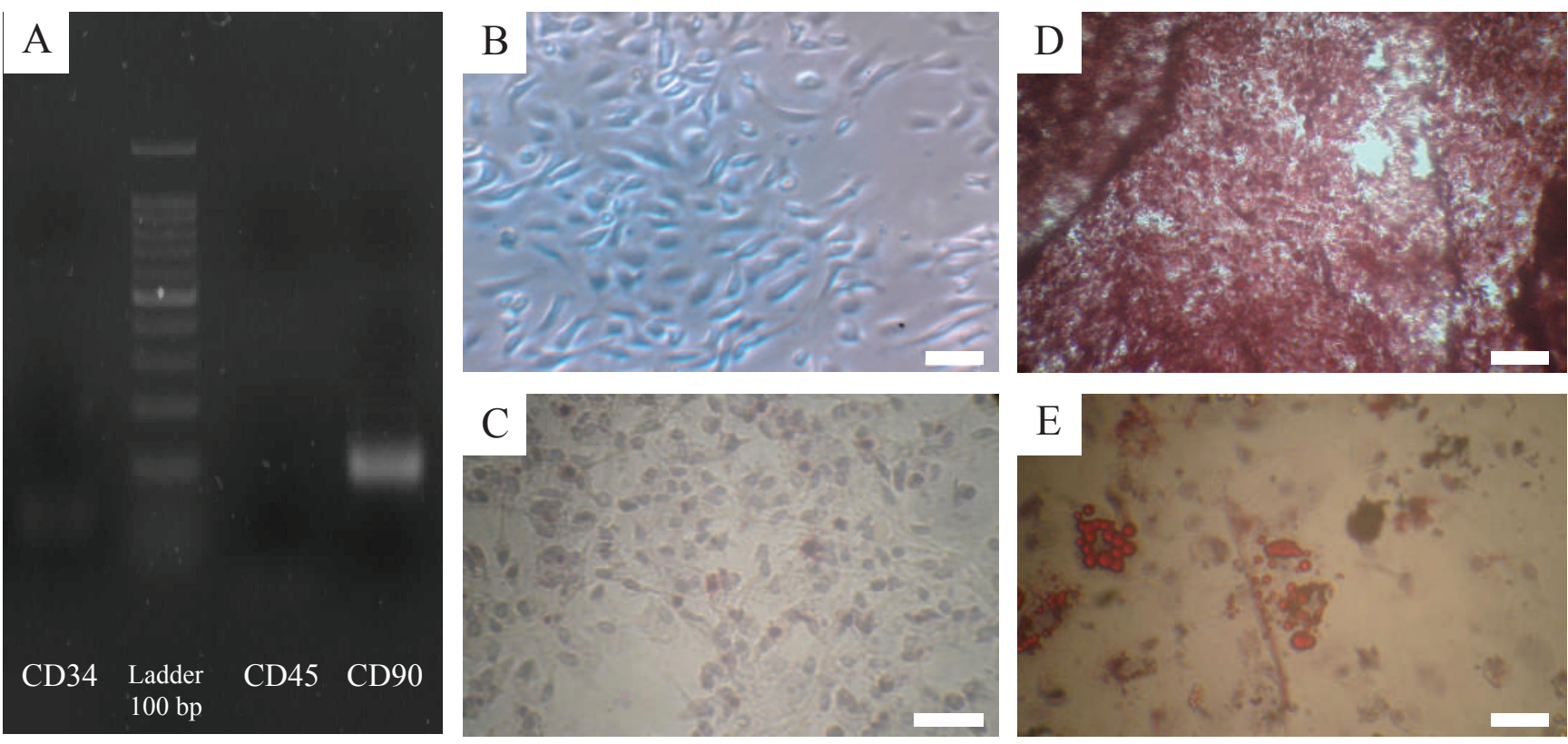

Figure 2. Characterization and differentiation of BM-MSCs. A: Agarose gel electrophoresis of products of reverse transcriptase polymerase chain reaction (RT-PCR) demonstrated that specific mesenchymal marker exists (CD90) compared with absence of specific hematopoietic marker (CD45and CD34) of mouse BM-MSCs; B: Spindle shape morphology of mouse BM-MSCs in passages $1(\times 40)$; C: Control group of BM-MSCs in passage $3(\times 100)$; D: BM-MSCs cultivated in osteogenic medium and stained with alizarin red $(\times 100)$; and E: In adipogenic medium and were stained with Oil Red $\mathrm{O}$ at day 21 after induction. White bars, $100 \mu \mathrm{m}$.

4A, 4B, 4C and 4D, respectively). There was no significant difference in the lumen diameter and area in seminiferous tubules in all three groups $(p>0.05)$ (Figure $4 \mathrm{E}$ and $4 \mathrm{~F}$, respectively). Spermatogenesis index was significantly increased in busul+CT group in comparison to the busulfan and control groups $(p<0.001$ and $p<0.05$, respectively) (Figure $4 \mathrm{G}$ ). In the busul $+\mathrm{CT}$ and control groups the number of tubules per unit area and numerical density of the tubules were less than the busulfan group $(p<0.001)$ and there was no significant difference in busul $+\mathrm{CT}$ and control groups $(p>0.05)$ (Figure 4H and 4I, respectively).

\section{Discussion}

Busulfan is a chemotherapeutic agent which is often used for the treatment of chronic myeloid leukemia (14) and is also used before bone marrow and stem cells transplantation $(15,16)$. Busulfan can inhibit cell division by sticking on one of DNA strands.(17) Gutierrez, et al., reported that compared to Swiss mice, Balb/C mice were more sensitive to the toxic effects of busulfan and were not fertile after 90 days of treatment.(18) Confirming it, Payehdar, et al., showed that two doses $(10 \mathrm{mg} / \mathrm{Kg})$ of busulfan with 21 days interval could induce irreversible azoospermia for more than 90 days.(11) Busulfan induces apoptosis and destroys mitotic cells including germ cells leading to azoospermia and infertility. (12) Cell transplantation was shown as a new approach for treatment of disorders such as azoospermia.(13) Hormonal therapies or surgical interventions were demonstrated with low efficacy in treatment of non-obstructive azoospermia.(19) In our study, BM-SCs were used in treatment of azoospermic Balb/C mice.

Cell therapy with MSCs is a new way for treatment of some disorders. BM-MSCs are able to differentiate between several mesodermal cell lineages including muscle, bone, fat, cartilage and other connective tissues cells.(20) MSCs secrete growth factors and cytokines that have antiinflammatory, immunosuppressive, anti-apoptosis, and proliferative effects that called 'trophic' activity.(21) Kuo, et al., reports that stem cell use improves complications of diabetes on the liver.(22) Also, stem cell use can reduce the complications of heart attack in pigs.(23) Sadraie, et al., showed that BM-MSCs can reduce the side effects of knee rubbing in the guinea pig.(24)

In this study it was shown that transplantation of $\mathrm{CD} 90^{+} / \mathrm{CD} 34 / \mathrm{CD} 45^{-} \mathrm{BM}-\mathrm{MSCs}$ in azoospermic Balb/C mice could successfully recover induce spermatogenesis. Similar findings demonstrated that Ad-SCs and BM-SCs could lead to recovery of fertility in the busulfan-induced azoospermia in rat $(6,9)$, hamster (25), and Guinea pigs 

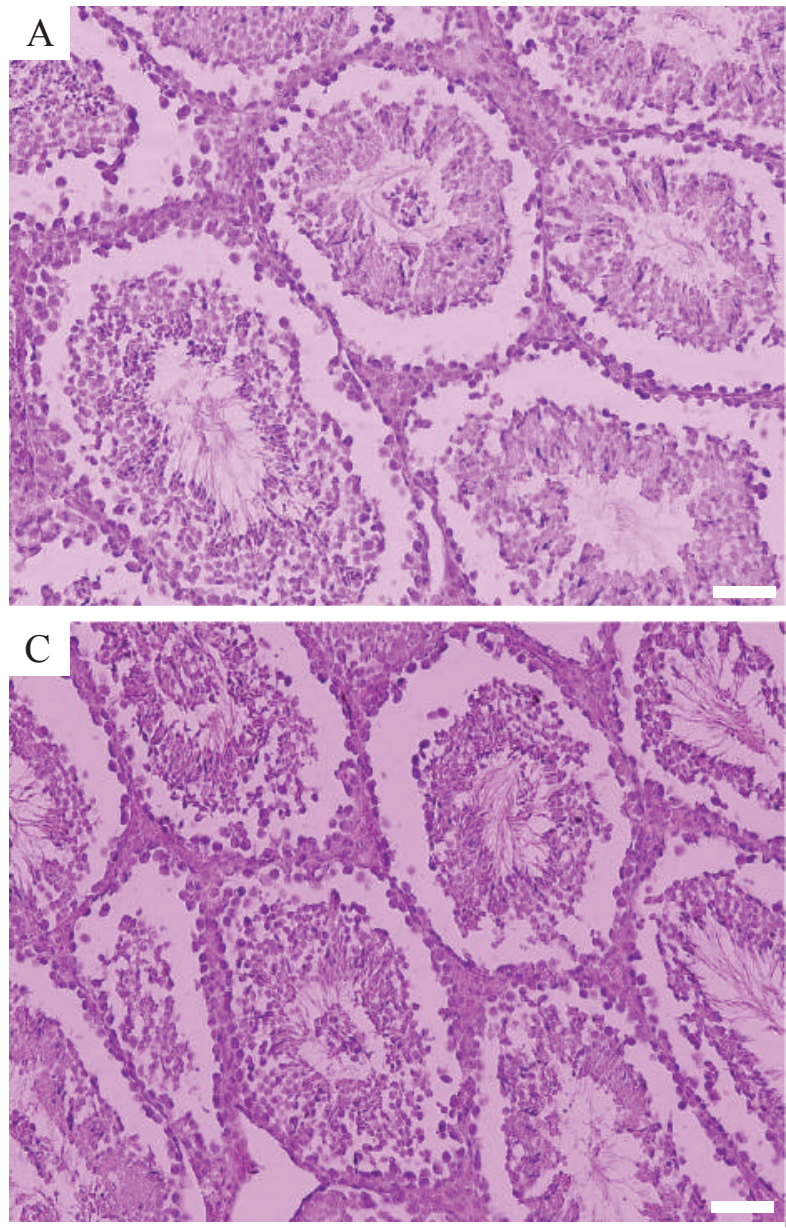

(26). Cakici, et al., showed that Ad-SCs transplantation after 12 weeks could recover busulfan-treated infertile male rats and induce spermatogenesis.(6) Lue, et al., reported that transplanted BM-SCs in busulfan-treated infertile mouse model could differentiate into germ, Sertoli, and Leydig cells.(27)

Several studies evaluated the differentiation potential of MSCs into spermatozoa in mice and rats regarding intraseminiferous tubule $(2,5)$ and intra-testicular injection of BM-MSCs (28). Monsefi, et al., showed that testis in infertile rats receiving BM-SCs could differentiate between germ cells in seminiferous tubules.(28) The differentiation potential of MSCs to spermatozoa was previously reported in rat $(2,9,29)$ and hamster $(25)$. But differentiation did not happen in all tubules.(6,9) Also, Nayernia, et al., reported that BM-MSCs could differentiation between germ cells in vivo. (30) Chen, et al., reported that human umbilical cord MSCs transplanted into seminiferous tubule of immunodeficient mouse could differentiate between sperm.(31) It was shown that cell transplantation in azoospermic animals may be species dependent.(25) Seminiferous tubules are responsible for regulation of spermatogenesis, and Sertoli

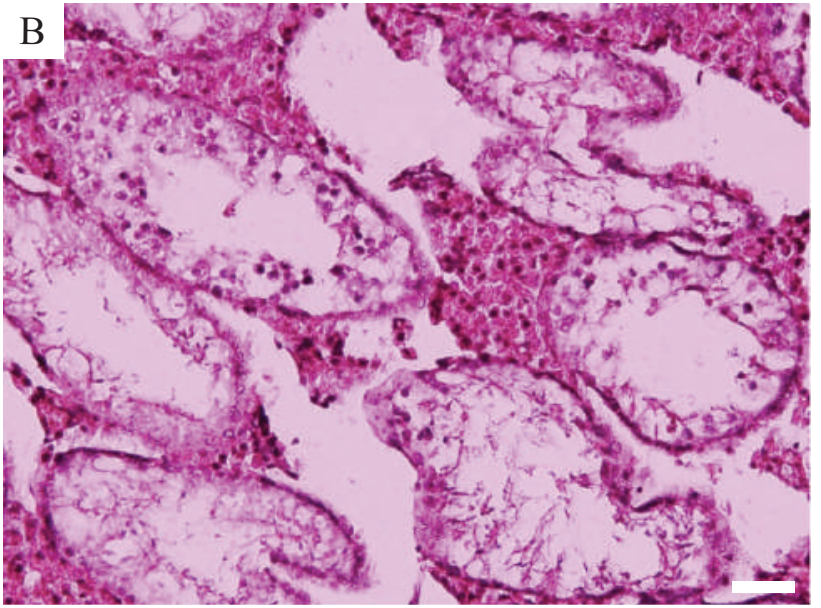

Figure 3. Histopathologic evaluation of seminiferous tubule in control, busulfan and busul+CT mice. A: Section of seminiferous tubules of normal control mouse. spermatogenic epithelium was condensed by tubules. B: Busulfan induced azoospermic mouse seminiferous tubules. The seminiferous tubules were partially empty and vacuolated spaces without germinal layer cells showed the lack of spermatogenesis. C: Sections of seminiferous tubules of treated mouse with BMMSCs. Most of tubules seemed to possess spermatogenic cells. White bars, $50 \mu \mathrm{m}$ (H\&E staining).

cells as immune-privileged for successful cell transplantation without the need for chronic immunosuppression therapy. The immune protective nature of Sertoli cells has been presented in another study.(32) Sertoli cells provide the microenvironment suitable for differentiation and proliferation of spermatogonial stem cells. Our findings, confirmed that BM-MSCs could reconstitute tubular microenvironment providing the chance for remained inactivated germinal cells to proliferate in the host seminiferous tubules.(25) There is evidence of the hypoimmunogenic nature of MSCs and so there is implication for allogeneic therapy.(31,33) Intravenous injection of BMSCs was shown to have immunosuppressive effects on production of anti-sperm antibody in allogeneic transfusion in mice after testis rupture.(25)

Mital, et al., reported that survival and protection of the cells after transplantation can be due to the immunological tolerance of Sertoli cells.(32) In seminiferous tubules, some points can be remarked after transplantation of stem cells: 1) blood-testis barrier as the immune privilege character plays an important role after stem cells transplantation in seminiferous tubules (34), 2) Also was shown that BM-MSCs 
A

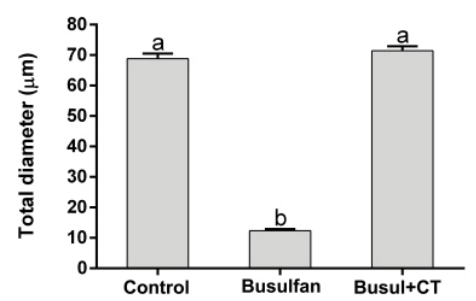

D

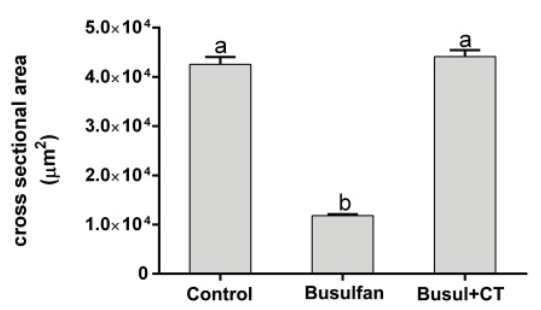

G

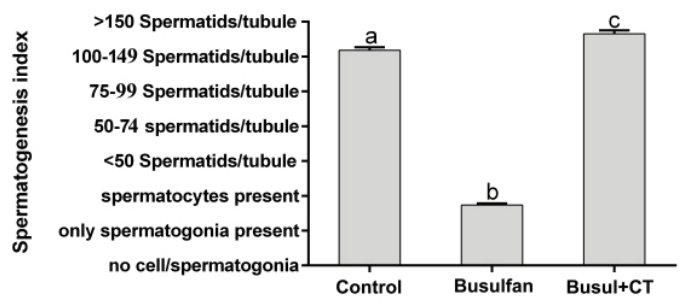

B

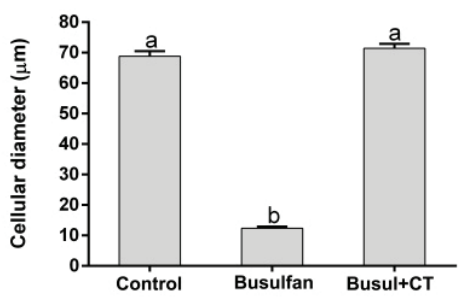

E

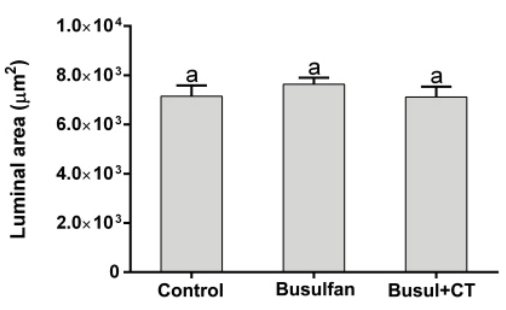

$\mathrm{H}$

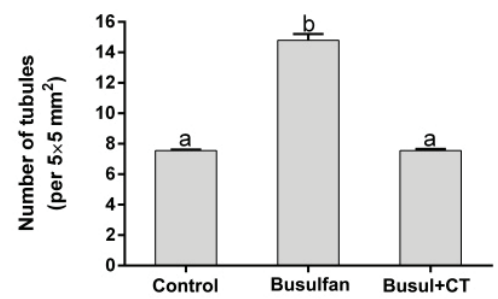

C

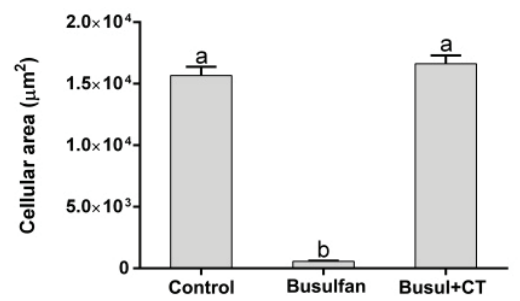

F

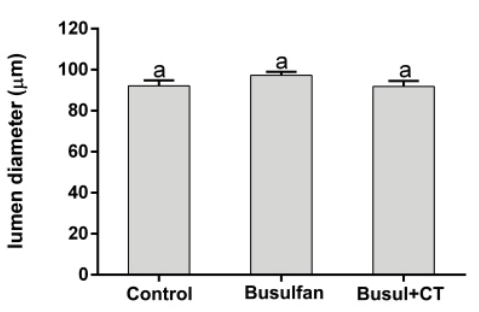

I

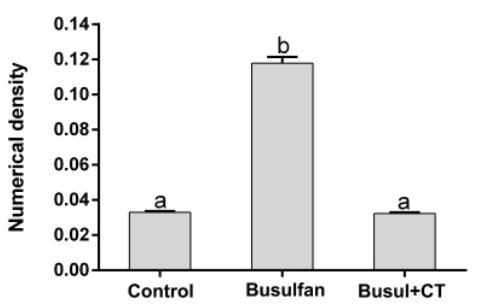

Figure 4. Mean and standard error of histomorphometric indices of seminiferous tubules in control, busulfan and busul+CT groups. A: Total diameter $(\mu \mathrm{m}), \mathrm{B}$ : Cellular diameter $(\mu \mathrm{m}), \mathrm{C}$ : Cellular area $\left(\mu \mathrm{m}^{2}\right), \mathrm{D}$ : Cross sectional area of the tubule $\left(\mu \mathrm{m}^{2}\right), \mathrm{E}: \mathrm{Luminal}$ area $\left(\mu \mathrm{m}^{2}\right), \mathrm{F}$ : Lumen diameter $(\mu \mathrm{m}), \mathrm{G}$ : Spermatogenesis index, H: Number of seminiferous tubules per unit area of testicular tissue, I: Numerical density of the seminiferous tubules. Different superscripts ( $\mathrm{a}, \mathrm{b}$ and $\mathrm{c}$ ) indicate statistically differences between groups $(p<0.05)$.

to have both hypoimmunogenic and immunosuppressive features after transplantation.(35) Therefore, transplantation of MSCs was considered as a method of choice for azoospermia cell therapy.

\section{Conclusion}

In this current study, histological and histomorphometric findings revealed that intra testicular transplantation of CD90+/CD34-/CD45- BM-MSCs in seminiferous tubules of busulfan-induced azoospermic Balb/C mice could differentiate between all types of germinal cells and recovered the spermatogenesis. BM-MSCs transplantation could be an effective method to treat non-obstructive azoospermia in patients undergoing chemotherapy such as busulfan and restore fertility in these patients. But more research must be done to verify this issue.

\section{Acknowledgment}

The authors wish to thank the Islamic Azad University and Shiraz University of Medical Sciences for their kind support.

\section{References}

1. Gudeloglu A, Parekattil SJ. Update in the evaluation of the azoospermic male. Clinics (Sao Paulo). 2013; 68: 27-34.

2. Zhang D, Liu X, Peng J, He D, Lin T, Zhu J, et al. Potential spermatogenesis recovery with bone marrow mesenchymal stem cells in an azoospermic rat model. Int J Mol Sci. 2014; 15: 1315165.

3. Vassilakopoulou M, Boostandoost E, Papaxoinis G, de La Motte Rouge T, Khayat D, Psyrri A. Anticancer treatment and fertility: Effect of therapeutic modalities on reproductive system and functions. Crit Rev Oncol Hematol. 2016; 97: 328-34. 
4. Meistrich ML. Effects of chemotherapy and radiotherapy on spermatogenesis in humans. Fertil Steril. 2013; 100: 1180-6.

5. Zahkook SAM, Atwa A, Shahat MM, Mansour AM, Bakry S. Mesenchymal stem cells restore fertility in induced azoospermic rats following chemotherapy administration. J Reprod Infertil. 2014; 5: 50-7.

6. Cakici C, Buyrukcu B, Duruksu G, Haliloglu AH, AksoyA, Isık A, et al. Recovery of fertility in azoospermia rats after injection of adiposetissue derived mesenchymal stem cells: The sperm generation. BioMed Res Int. 2013; 2013: 1-18.

7. Asadi-Yousefabad S-L, Khodakaram-Tafti A, Dianatpour M, Mehrabani D, Zare S, Tamadon A, et al. Genetic evaluation of bone marrowderived mesenchymal stem cells by a modified karyotyping method. Comp Clin Pathol. 2015; 24: 1361-6.

8. Mahdiyar P, Zare S, Robati R, Dianatpour M, Torabi K, Tamadon A, et al. Isolation, culture, and characterization of human dental pulp mesenchymal stem cells. Int J Pediatr. 2014; 2: 44.

9. Mehrabani D, Hassanshahi MA, Tamadon A, Zare S, Keshavarz S, Rahmanifar F, et al. Adipose tissue-derived mesenchymal stem cells repair germinal cells of seminiferous tubules of busulfan-induced azoospermic rats. J Hum Reprod Sci. 2015; 8: 103-10.

10. Ehninger A, Trumpp A. The bone marrow stem cell niche grows up: mesenchymal stem cells and macrophages move in. J Exp Med. 2011; 208: 421-28.

11. Payehdar A, Hosseini E, Mehrabani D, Forouzanfar M. Busulfan treatment effects on testicular tissue and serum levels of antimullerian hormone and testosterone in adult mice. Indones Biomed J. 2017; 9: 106-12.

12. Panahi M, Karimaghai N, Rahmanifar F, Tamadon A, Vahdati A, Mehrabani $\mathrm{D}$, et al. Stereological evaluation of testes in busulfaninduced infertility of hamster. Comp Clin Pathol. 2014; 24: 1051-6.

13. Rahmanifar F, Tamadon A, Mehrabani D, Zare Sh, Abasi S, Keshavarz $\mathrm{S}$, et al. Histomorphometric evaluation of treatment of rat azoospermic seminiferous tubules by allotransplantation of bone marrow-derived mesenchymal stem cells. Iran J Basic Med Sci. 2016; 19: 653-61.

14. Suttorp M, Millot F. Treatment of pediatric chronic myeloid leukemia in the year 2010: use of tyrosine kinase inhibitors and stem-cell transplantation. Hematology Am Soc Hematol Educ Program. 2010; 2010: 368-76.

15. Le Bourgeois A, Lestang E, Guillaume T, Delaunay J, Ayari S, Blin N, et al. Prognostic impact of immune status and hematopoietic recovery before and after fludarabine, IV busulfan, and antithymocyte globulins (FB2 regimen) reduced-intensity conditioning regimen (RIC) allogeneic stem cell transplantation (allo-SCT). Eur J Haematol. 2013; 90: 177-86.

16. Nieto Y, Thall P, Valdez B, Andersson B, Popat U, Anderlini P, et al. High-dose infusional gemcitabine combined with busulfan and melphalan with autologous stem-cell transplantation in patients with refractory lymphoid malignancies. Biol Blood Marrow Transplant. 2012; 18: 1677-86.

17. Iwamoto T, Hiraku Y, Oikawa S, Mizutani H, Kojima M, Kawanishi S. DNA intrastrand cross-link at the 5'-GA-3' sequence formed by busulfan and its role in the cytotoxic effect. Cancer Sci. 2004; 95: 454-58.

18. Gutierrez K, Glanzner WG, Chemeris RO, Rigo ML, Comim FV, Bordignon $\mathrm{V}$, et al. Gonadotoxic effects of busulfan in two strains of mice. Reprod Toxicol. 2016; 59: 31-9.
19. Berookhim B.M., Schlegel. Azoospermia due to spermatogenic failure. Urol Clin. North Am. 2014; 41: 97-113.

20. Caplan AI. Adult mesenchymal stem cells for tissue engineering versus regenerative medicine. J Cell Physiol. 2007; 213: 341-7.

21. Caplan AI, Dennis JE. Mesenchymal stem cells as trophic mediators. J Cell Biochem. 2006; 98: 1076-84.

22. Kuo TK, Hung SP, Chuang CH, Chen CT, Shih YR, Fang SC, et al. Stem cell therapy for liver disease: parameters governing the success of using bone marrow mesenchymal stem cells. Gastroenterology. 2008; 134: 2111-21.

23. Amado LC, Saliaris AP, Schuleri KH, St John M, Xie JS, Cattaneo S, et al. Cardiac repair with intramyocardial injection of allogeneic mesenchymal stem cells after myocardial infarction. Proc Natl Acad Sci USA. 2005; 102: 11474-9.

24. Sadraie MR, Mehrabani D, Vahdari A. Comparison of therapeutic effects of bone marrow mesenchymal stem cells and liquid culture environment (secreta) in the treatment of induced knee abrasion created in Guinea Pigs. Armaghane danesh. 2016; 20: 65165 .

25. Tamadon A, Mehrabani D, Rahmanifar F, Raayat Jahromi A, Panahi $\mathrm{M}$, Zare $\mathrm{S}$, et al. Induction of spermatogenesis by bone marrowderived mesenchy-mal stem cells in busulfan-induced azoospermia in hamster. Int J Stem Cells. 2015; 8: 134-45.

26. Hajihoseini H, Vahdati A, Hosseini E, Mehrabani D, Tamadon A. Induction of spermatogenesis after stem cell therapy of azoospermic guinea pigs. Vet Arhiv. 2017; 87: 333-50.

27. Lue Y, Erkkila K, Liu PY, Ma K, Wang C, Hikim AS, et al. Fate of bone marrow stem cells transplanted into the testis : potential implication for men with testicular failure. Am J Pathol. 2007; 170: 899-908.

28. Monsefi M, Fereydouni B, Rohani L, Talaei T. Mesenchymal stem cells repair germinal cells of seminiferous tubules of sterile rats. Iran J Reprod Med. 2013; 11: 537-44.

29. Sabbaghi MA, Bahrami AR, Feizzade B, Kalantar SM, Matin MM, Kalantari $\mathrm{M}$, et al. Trial evaluation of bone marrow derived mesenchymal stem cells (MSCs) transplantation in revival of spermatogenesisin testicular torsion. Middle East Fertil Soc J. 2012; 17: 243-9.

30. Nayernia K, Lee JH, Drusenheimer N, Nolte J, Wulf G, Dressel R, et al. Derivation of male germ cells from bone marrow stem cells. Lab Invest. 2006; 86: 654-63

31. Chen H, Tang QL, Wu XY, Xie LC, Lin LM, Ho GY, et al. Differentiation of human umbilical cord mesenchymal stem cells into germ-like cells in mouse seminiferous tubules. Mol Med Rep. 2015; 12: 819-28.

32. Mital P, Kaur G, Dufour JM. Immunoprotective sertoli cells: making allogeneic and xenogeneic transplantation feasible. Reproduction 2010; 139: 495-504.

33. Barry FP, Murphy JM. Mesenchymal stem cells: clinical applications and biological characterization. Int J Biochem Cell Biol. 2004; 36 : 568-84.

34. Meinhardt A, Hedger MP. Immunological, paracrine and endocrine aspects of testicular immune privilege. Mol. Cell Endocrinol. 2011; 335: 60-8.

35. Ai J, Ebrahimi S, Khoshzaban A, Jafarzadeh Kashi TS, Mehrabani D. Tissue engineering using human mineralized bone xenograft and bone marrow mesenchymal stem cells allograft in healing of tibial fracture of experimental rabbit model. Iran Red Crescent Med J. 2012; 14: 96-103. 